Basta/Prou

Microrrelatario

anar a l'index 


\title{
Basta/Prou Microrrelatario
}

\author{
Dori Valero (coord.)
}

El desafío para la erradicación de la violencia contra las mujeres del Instituto Universitario de Estudios Feministas y de Género de la Universitat Jaume I Purificación Escribano 
Primera edició: març 2013

Edició a càrrec de:

Dori Valero Valero

Assessorament editorial:

Carme Pinyana i Garí

Disseny i maquetació:

Drip Studios

Fotografia de portada: Sinfonia de piedra, Wences Rambla

Instituto Universitario de Estudios Feministas y de Género Purificación Escribano.

Universitat Jaume I de Castelló

www.if.uji.es

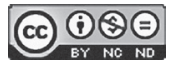

ISBN: 978-84-695-7658-8

DOI: http://dx.doi.org/10.6035/BastaProu.2013 


\title{
Basta/Prou. Microrrelatario
}

\author{
Dori Valero (coord.)
}

María Luisa Agost, Miguel Alayrach Martínez, Nieves Alberola Crespo, Inma Alcalá García, Manel Alonso i Català, Amador Antón, Eugenia Aragó, Lledó Aragó, Ali Brancal, Luisa Busto, Juncal Caballero Guiral, Lidón Caballero Guiral, Cristina Cabedo Laborda, Fernando Cid Lucas, Inma Collado, Carmen Corona Marzol, M. Creu Marín, Manolo Dos Ramos, Sebastián Esparducer Gargallo, Estudiantado de $4^{\circ}$ de Grado en Publicidad de la UJI, Maria Estupiñá Mulet, Verónica Fernández Guillén, Carmen María Fernández Nadal, Vicenta Gallego, Javier García, Cristina García Ramírez, Inés García Ramírez, Luis Gil Lahuerta, Elisa Iniesta Pérez de Gracia, Ana María Julián Edo, Cristina Laborda Martínez, Saloua Laghrich, Teresa Lampérez Alonso, Luz Marina Álvarez, Isabel Lloret Sos, José Ramón Martínez García, Pasqual Mas, María del Carmen Merino Pastor, Rosa Miró i Pons, Rosa Montañés, Ma Cristina Morales Carrasco, Osadía, Caterina Palatsí Pinyana, Elena Pérez Senabre, Carme Pinyana i Garí, Tahirisoa Rakotonanahary, Carmen Ramírez, Rosario Raro, Eva Sales Fortanet, Dora Sales Salvador, Lidón Sancho Ribés, Maribel Sancho Ribés, Pilar Sanjulián, Verónica Segoviano Marinas, Carmen Senabre Llabata, Marta Senent Ramos, María José Senent, Miriam Solsona Andrés, Rosalía Torrent Esclapés, Adela Torres, Dori Valero Valero, Ferrana Vila, Amparo Zacarés 


\section{PRÓLOGO}

Basta/Prou es el resultado de El desafio por la erradicación de la violencia contra las mujeres que el Instituto Universitario de Estudios Feministas y de Género Purificación Escribano de la Universitat Jaume I lanzó en los Diez dias contra la violencia de género 2012.

Cada relato es un honesto y comprometido alegato por la no violencia contra las mujeres y una denuncia de la situación que muchas mujeres siguen sufriendo, a pesar de los avances en materia de igualdad. Es la violencia más primaria, que más allá del dolor físico provoca dolor psicológico y emocional al anular cualquier posibilidad de construir su propia identidad, su SER.

Las autoras y autores que participan en la presente edición de El desafio por la erradicación de la violencia contra las mujeres quieren poner, con unas pocas letras, su granito de arena en la denuncia del maltrato por cuestiones de género. Además de manifestar su apoyo al cambio social hacia una sociedad igualitaria y sin violencia entre personas sea cual sea su identidad sexual. 


\section{PRÒLEG}

Basta/Prou és el resultat de El desafiament per l'eradicació de la violència contra les dones que l'Institut Universitari d'Estudis Feministes i de Gènere Purificación Escribano de la Universitat Jaume I va llançar en els Deu dies contra la violència de gènere 2012.

Cada relat és un honest i compromès al-legat per la no violència contra les dones i una denúncia de la situació que moltes dones segueixen patint, tot i els avenços en matèria d'igualtat. És la violència més primària, que més enllà del dolor físic provoca dolor psicològic i emocional en anul-lar qualsevol possibilitat de construir la pròpia identitat, el seu SER.

Les autores i autors que participen en aquesta edició de El desafiament per l'eradicació de la violència contra les dones volen posar, amb unes poques lletres, el seu granet de sorra en la denúncia del maltractament per qüestions de gènere. A més de donar suport al canvi social cap a una societat igualitària i sense violència entre persones siga quina siga la seua identitat sexual. 


\section{A VIDA O MUERTE}

María fingió dormir, esa y todas las noches se sintió como una puta cuando le hizo el amor. Para él era una posesión, como un mueble, un klinex de usar y tirar. Miró la foto de su hijo de diez años y en ese momento sintió la fuerza de un búfalo. Llevó a cabo lo ensayado mentalmente: preparó la maleta con lo necesario, no dejó pistas de su inminente viaje. Necesitaba huir o se suicidaría. Recogería al niño del colegio y se irían a algún lugar lejano. Serían felices y empezaría de cero, con heridas sangrantes que esperaba cicatrizaran. Era vital recuperar el tiempo perdido. 


\section{INESPERADO}

Qué ironías tiene la vida, justo al dejar de amarle, volví a sonreír.

Miguel Alayrach 


\section{EL VELO HIERÁTICO DE LA VIOLENCIA DE GÉNERO}

OCULTAR. En la cocina, en el salón, en el dormitorio...

«¿Ve las huellas de sus manos en su cuello?»

SORTEAR. $\quad$ En el patio de la casa de los abuelos...

"...empuñó un arma»...

«...suerte que sus hermanos lo sujetaron».

HUIR. «iiTAXI!!»

...quizás...

TESTIMONIAR. «¿Y los niños?» ... a una casa de acogida.

Cuando se les pregunta, guardan silencio.

Postergar sine die la DENUNCIA

$\mathrm{O}$

LEVANTAR EL VELO Y RENACER.

Nieves Alberola Crespo 


\section{HISTORIA CONTADA}

La historia ya estaba contada, idénticas palabras, las mismas lágrimas definiendo miradas, pero siempre era una historia nueva. Los sentimientos rotos, las palabras calladas, los sueńos quebrados formaban parte de la propia piel de cada mujer que relataba la historia. A cada instante era más la distancia y ya el miedo se había vencido, solo quedaba seguir otra vida distinta, el pasado estaba teñido por el rojo de la sangre. El futuro era ya diferente y nuevo.

Inmaculada Alcalá García 


\title{
PLORES
}

Plores com un infant a qui li han llevat un joguet. Plores. No has entès res. Mai no vas aprendre a conjugar els verbs estimar, respectar. Sí que li deies et vull amb una naturalitat apresa de la cultura patriarcal que mamares. Mai no féreu l'amor, no sabies construir un univers d'amables passions des d'on alçar el vostre projecte de vida en comú. La prenies com si et pertanyés. I has hagut de pintar-li la pell de blaus perquè s'adonés que navegava amb tu al timó per una mar grisa cap als abismes. Plores, no tens dret a fer-ho.

\author{
Manel Alonso i Català \\ www.escriptors.cat/autors/alonsom
}




\section{HAIKUS CONTRA LA VIOLENCIA}

\author{
I \\ Y las palomas \\ rehusaban comer \\ en manos viles.
}

II

Heriste senos

con tus uñas y dientes, no cesa la ira.
III

Aquellos labios

destrozados han vuelto

a hablar de siembra.

\author{
IV \\ La armonía es \\ conversación perenne \\ sin dominar.

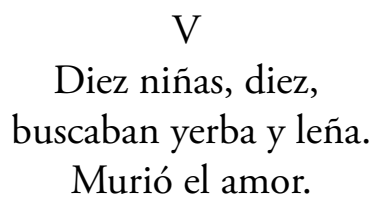

Amador Antón 


\section{SENSE PARAULES}

Al principi li vaig dir:

SÓC TOTA TEVA.

SÓC TOTA

sóc

Sss

El final:...

Eugènia Aragó 


\section{L'ESCALA}

Pujava l'escala, amb un somriure especial, un somriure d'aquells que il.luminen els ulls. Anava agafada de la mà. Era el que volia fer, era el que desitjava. Pel seu cap passaven molts pensaments i volava, s'enlairava a poc a poc...

Després va baixar l'escala, sabia que mai la tornaria a pujar, que mai tornaria a compartir aquella mà, ni aquell cos. Li rodava una llàgrima per la cara, havia estat l'última vegada. La tristor era dolça... comptava els graons, la decisió ferma la portaria cap a la llibertat. Decideix tu.

Lledó Aragó 


\section{LUCIDA SANS}

Tot té un final. I aquest és el nostre final definitiu. Vaig a dir-t'ho, per fi. Ara ja no tinc por. Ja no em fas por. No em tornaràs a posar la mà al damunt, no podràs tornar a humiliar-me. S'han acabat els cops, les palisses i els càstigs absurds. Mai més controlaràs el que faig, el que dic, amb qui vaig, el que pense, el que desitge. Per fi sóc lliure i no tens poder sobre mi.

«Vol dir que no cabrà tot açò a la làpida de ma mare? En Lucida sans, era la seua font de lletra preferida.»

Ali Brancal 


\section{A ELLA SIEMPRE LE HABÍA GUSTADO EL ROJO INTENSO DE SU BARRA DE LABIOS}

El lápiz de labios temblaba entre sus dedos... «Yo no necesito espejos», solía afirmar, «me veo en los ojos de los hombres que me miran»... Pero allí, sólo estaban ella y la imagen proyectada por el desconchado espejo del baño, tan gélido y cruel como la mañana. El rostro marcado se le antojaba hoy desconocido y sentía en el cuerpo el punzante dolor de aquel último portazo cargado de desprecio. Pero esta vez, incapaz de redibujar el lacerado perfil de su boca, la barra cosmética se estrelló contra el cristal de azogue y una vociferante mancha rouge passion desgarró, concluyente, el ritual diario.

Luisa Busto 


\section{SEÑORAS, POR FAVOR, LIMPIEN}

Pues sí señoras, por fin ese día llegó. Me levanté de la cama con una desconocida y agradable energía y me fui a por la escoba para realizar las labores domésticas. Él se puso delante de mí y camino del lavabo me regaló, como cada mañana, un gruñido apestoso mientras me apartaba de un manotazo hacia un lado.

De repente, como tantas veces había ocurrido en mi imaginación, yo me hice grande, muy grande hasta tal punto que él llegó a ser sólo una mota de polvo insignificante $\mathrm{Y}$ sí, señoras, me puse el delantal y barrí.

Barrí con tanto brío que todo a mi alrededor brilló y la mota de polvo insignificante desapareció. Entonces, con una sonrisa en la cara, me quité el delantal, me fui al lavabo y seguí limpiando, pero esta vez, me limpié a mí: limpié mi cara, mi cuerpo, mi mente, mi alma y mi vida y me fui a la oficina. 


\section{L' ANIVERSARI}

Amb menys forces, va preparar el mateix sopar per aquest segon aniversari, va comprar el mateix vi blanc, va col-locar les mateixes flors fresques i es va maquillar el doble de blaus.

Cristina Cabedo Laborda 


\section{TRES HAIKUS}

I

¿Quién recuerda ahora

el sake para dos del templo? Polillas.

II

Se te hizo tarde, ordenando su ropa, para ver flores.

III

Mirar estrellas, mas no para contarlas. Aún tarda en volver.

Fernando Cid Lucas 


\section{SI UNA DONA ET DIU NO}

Si una dona et diu NO...

escolta-la perquè té una raó.

Si una dona et diu No, NO...

respecta-la, sap el que vol.

Si una dona et diu No, no i NO...

accepta-ho: no saps escoltar,

no saps respectar,

has perdut el nord.

Imma Collado 


\section{CAMPO DE AMAPOLAS}

Durante un tiempo languidecí, como una corola desmayada, mirando al suelo.

Cada día se coloreaban de púrpura los suspiros escondidos, y pétalos de sueños acolchaban el manto rojo de mi alcoba.

Hasta que un día, me encontré erguida en el viento alado. Me habían crecido fornidos tallos verdes, dispuestos a sustentar imaginadas ilusiones.

Alcé la mirada aún incrédula, y divisé un camino intransitado. ¡Era mío!

Ansiaba llenarlo con el aroma imperceptible de mi paso.

Entonces pensé, tenías razón, desconocida amiga, cuando me decías entre el susurro y el grito:

si te aferras fuertemente volverás a florecer, y verás el Campo de Amapolas. 


\title{
VA PENSAR QUE NO HI HAVIA SORTIDA
}

\author{
Va pensar que no hi havia sortida. \\ Va somiar que sí. \\ Ho va intentar amb força $\mathrm{i}$ \\ ho va aconseguir.
}

M. Creu Marin 


\section{EL ÚLTIMO PICNIC}

No había más que hablar. Nos vamos de excursión, rugió él. El porqué de tanta insistencia era un cliché y ella lo sabía: quiere que parezca un accidente. No se equivocaba, él pensaba asesinarla, después de todo ya no podría retenerla más. Las amenazas, los golpes ya no servían de nada. Más tarde, ella le dijo, ponte al lado de ese enorme cactus, ahí hay una foto preciosa. Él hinchó el pecho, pensaba que eso le daba un aspecto todopoderoso, con el horizonte a sus espaldas, sólo aire y nubes. Y aquel enorme falo con pinchos a su lado, todo muy apropiado. Ella ajustó el objetivo de la cámara. El sol rebotó en el cristal y un destello cegador produjo un violento estornudo en él. Un estornudo fótico lo llaman. El impulso le hizo perder el equilibrio. Un risco, una caída, todo fue tan normal. Horas más tarde, en comisaría admiraron el resultado. Un par de piernas flotantes, del revés, incompletas, se recortaban contra una esponjosa nube. ¡Jesús!, exclamó el comisario al ver aquella fotografía.

Manolo Dos Ramos 


\section{ECOS EN EL PATIO}

Siempre a la misma hora, cercana la medianoche, antes o después del ruido metálico y frío del camión de la basura, junto con el hedor a gasoil y desperdicios. Desde el $2^{\circ}-\mathrm{B}$, dos alturas más abajo, golpes secos cortaban el silencio, invadían todas las noches, el patio comunitario. Algunos gritos, no siempre, y un llanto contenido, que impregnaba las paredes junto a los tendederos, y se clavaba en las conciencias. Ocho años, los mismos años de la niña pequeña del $2^{\circ}-B$. Hoy, ya hace tres noches del fatal desenlace, hoy nuestro patio corrompido, nos señala, desde el ruidoso silencio que lo envuelve.

Sebastián Esparducer Gargallo 


\section{SUPERFLUO VESTIDO}

Si tuviera capacidad para conseguir mi meta.

Tengo heridas por todo el cuerpo y no siento nada.

Si supieses qué pienso realmente de ti.

Buscaré refugio en los bosques de fresas verdes.

Si esas lágrimas no impactaran en el suelo despedazándose como cristales rotos, no pensaría que su dolor fuera tan intenso y desmedido.

Conseguiré ser libre.

Si todas las mujeres se unen,

soy yo misma.

Si me entretengo a la salida del trabajo...

volaré lejos.

Si aprendiera a soñar un poco más...

que el amor le gane a la guerra.

Mireia Campos Ferrer, Oliver Calabuig, Antonella López Milanesio, Ángela Edo Domenech Anna Artana Bodi, Isabel Cebrià Zapata, Maria Miñano Rodríguez, Victoria Sampietro Tolosana, Sara Martí de Veses Bochons, Noelia López Vega, Estefanía Pastor Sampedro, Jorge Olmeda Gil, Javi Sahuquillo Grimaldos, Juan Manuel Caurin $4^{\circ}$ Grado de Publicidad y Relaciones Públicas. Universitat Jaume I 


\section{FERMA}

Tinc fred, obro els ulls, lentament reconec el lloc. Ja no està. Covard. La impotència aviat es converteix en ràbia. Entumida, s'entrecreuen els pensaments. Fugir, on? Resistir. Alliberar-se, continuar, escapar, sobreviure... Lluitar!

Decidida, entre llàgrimes amargues, em poso en peu. No donaré un pas enrere.

Maria Estupiñá Mulet 


\section{ERES MI VIDA}

-Eres mi vida, nadie te va a querer como yo...

-Abrázame, te quiero...

«Tú me escuchas, me consuelas, me comprendes, tú lo eres todo, sabes que es lo mejor para mí, por eso te enfadas, por eso me gritas, es mi culpa, me lo merezco, perdón.

Pero No, no puedo con más golpes, insultos, humillaciones... me hundes.

Miro la vida a través de tu cristal, el mío ya no vale para nada, ha quedado anulado, anulada mi vida, la relación con mi familia, con mis amigos, ¿para que necesito yo a nadie si te tengo a ti?»

-Eres mi vida, nadie te va a querer como yo...

-Ojalá nunca nadie me quiera como tú, mi vida es sólo mía.

Verónica Fernández Guillén 


\section{CADÁVER EXQUISITO EN RED}

Me levanto y pienso: si él me amara, si me respetara y fuera capaz de no hacerme daño. Miro la línea del horizonte con una sensación de angustia terrible pero y si mi mundo fuera distinto, si me atreviera a decírselo a alguien, pero me duele todo, no tengo fuerzas para llegar al teléfono. Estoy intranquila, hay a mi alrededor un murmullo incesante. Me estremezco. Si él no estuviera yo sería feliz, mi mano me duele, pero por fin consigo marcar los números 016 . Hoy por fin he podido dormir. SUEÑO, SUEÑO, SUEÑO, SUEÑO, SUEÑO.

Carmen Maria Fernández Nadal y Juncal Caballero Guiral 


\section{EL FIN}

Cuando era pequeño descubrió el sabor del poder peleándose con un amigo. Sintió que levantando su puño y golpeándole con fuerza sobre su yo se crecía. Ese acto tan sencillo para él, le parecía que era una forma de relacionarse con los demás y le daba el título de machote. Después descubrió a las mujeres y con ellas se sintió más fuerte todavía. Ellas no peleaban, utilizaban sus manos para acariciar y eso le ponía frenético. Entonces golpeaba con más fuerza sus puños y sus palabras y su ira tuvo un FIN.

Vicenta Gallego 


\section{TELARAÑA}

No estoy muerta, o sí, ya no lo sé. Sus golpes nunca me hicieron daño, sus palabras sí: «cállate perra». La gente me solía decir que lo denunciara o terminaría visitando a esas otras mujeres, que durante el año, marcharon forzadas para no volver. No pude hacerlo, era incomprensible. El amor que sentía por él me tapó los ojos. Cuando me di cuenta de la realidad, ya fue demasiado tarde: fui una mariposa en una telaraña. No estoy viva, o sí, qué más da. Aquí no estoy sola y tengo libertad.

Javier García 


\section{NADIE}

-No sé qué pasó. Yo solo estaba paseando por la calle, hablando por el móvil y con bolsas de la ropa que acababa de comprarme. De repente, se echaron sobre mí como lobos. Eran dos, pero jóvenes, ¡no te creas! Y empezaron a golpearme con algo que llevaban en las manos. ¡Casi me matan! Nadie se paró, nadie intervino. ¡Fue horrible!

-Me lo puedo imaginar, ¡qué horror! Después se quejan de que haya guetos en las ciudades, pero... ¿`ómo puede un gay pasear tranquilo si no?

Cristina García Ramírez 


\section{NO TODOS SON ASÍ}

- ¿Y cómo piensas ir al mercado, hacer la compra y volver a casa en media hora? No debería ser un problema el que te entretengas un rato con tu hermana, antes de volver. Pero ¡si estás siempre en casa! Ya no te vemos, cada día pareces más triste y cansada.

-Es que si se entera. El problema es que no sé cocinar, con el trabajo y los niños, la casa está siempre hecha un lío y claro, él se enfada. Él es así. ¿No son todos así?

-No hermana, no lo son y el miedo, nunca es el camino.

Inés García Ramírez 


\section{CON CADENAS Y UN CAMINO TRAZADO A GOLPES}

Lo más duro para ella fue que el amor de su vida la tuviera sometida a su antojo, sin coherencia ni razón alguna. Cuando ella intentaba salir del camino labrado a golpes, otro golpe la corregía. Otro golpe que en las noches se convertía en caricias, que le hacían dudar si eso era lo correcto. Las caricias le ayudaban a coger aire. En las mańanas afloraban las amenazas y en la tarde de nuevo la sometía, sin razón, sí, pero sometida, hasta que un buen día sus ojos se abrieron en las amenazas de la mañana y decidió romper las cadenas que le ataban. Con miedo, sí, pero con esperanza de volver a vivir.

Luis Gil Lahuerta 


\section{SOBREVIVIENTE}

Siento dentro de mí una nueva vida que palpita. Me he ausentado de mi vetusta existencia, para explorar nuevas lindes. Mis expectativas se han multiplicado por mil en sólo una hora de distancia. He dejado atrás un pasado cargado de melancolía, ausencias, miedo y reproches. No es demasiado tarde para empezar. Soy demasiado joven para rendirme. Ahora tengo un motivo más para emprender mi camino. Soy fuerte. Siento dentro de mí una nueva vida que palpita.

Elisa Iniesta Pérez de Gracia 


\section{UN HOMBRE EN MI CASA}

Hay un hombre en mi casa. Me insulta, me mira con odio, y amenaza con matarnos a mí y a mis hijos si no hacemos lo que él nos dice. Yo no puedo dejar de llorar, estoy muy asustada. Le digo que no lo haga, pero no me atrevo a mirarle a los ojos. Le digo que haremos lo que él nos pida, pero él sigue cada vez más violento como si le enojara mi concesión sin límites, mi allanamiento humillado... Lee el pánico en mi mirada, mis hijos lloran calladamente. Hace diez años le dije que SÍ, ante Dios, dice él. Tengo un arma escondida desde hace tiempo. Quizá esta noche me regale flores y le vuelva a perdonar, porque sólo quiere lo mejor para mí.

Ana María Julián Edo 


\section{TOT ENRERE}

-la nina, el conte...

-la play, la bici, els deures...

-la cartilla de la Seguretat Social, la roba, les fotos...

-Teresa...!

En escoltar la seua veu abraçà la filla mentre el fill se li aferrava a la cama. Eixint es vegé el rostre a l'espill del rebedor, l'ull s'emblavia, però la boca ja no sagnava.

Entropessà i perdé una sabatilla en escoltar de nou la seua veu: Tere!

No tornà per arreplegar-la. Tot i la borratxera, ell tindria forces per a seguir-los si se n'adonava.

Arrancaren a córrer en plena nit i en pijama.

Una casa d'acollida els salvaria de l'infern, encara que exigís per allò deixar-ho TOT ENRERE.

Cristina Laborda Martinez 


\section{EL PROBLEMA NO ES ELLA}

Después de cuatro meses decide hablar y comunicarse con quien puede ayudarla. Él ha cambiado mucho, ya no sale de la habitación. Quiere sexo todas las mañanas y todas las noches. Ella no. Está cansada y él es muy bruto. Le exige cosas vergonzosas. Sus hijos duermen en la habitación de al lado, ella le ruega que no siga, que no la agarre tan fuerte de los hombros y de las muñecas porque le duele, pero él sigue. Le dice que es suya, que tiene que cumplir con sus obligaciones de esposa.

El día empieza y ella sale a buscar faena con que dar de comer a sus hijos... y a él. No se atreve a ir a un juzgado. Tiene vergüenza y miedo.

Hoy ha hablado y contado su infierno. Se siente arropada en silencio. Él no puede saberlo. El psiquiatra le dice que el problema no es ella, que no necesita ninguna medicación. Acaba de empezar.

Saloua Laghrich 


\section{TULIPANES}

Ya había dejado de pensar en los malos ratos, vuelto a sonreír y bailar, cuando sonó el teléfono. Sabía que era él. Contestó al vacío: «yo también te echo de menos, sí, te he perdonado, sí, yo también quiero, sí, estoy guapa». Siguió un largo silencio, y antes de que colgase le oyó decir: «llegaré esta noche».

Encendió la chimenea, puso su música y preparó una buena mesa. Se duchó, eligió la corsetería y un vestido sugerente. Pegada a la ventana, pensaba en su voz cálida, en su sonrisa, en retomar proyectos. Entonces, le vio atravesar el jardín desaliñado, cansado. Apenas cruzó la puerta entreabierta, ella corrió a sus brazos. Apartándola, sin mirarla le ordenó: acaríciame. Lo hizo hasta que su rostro estuvo bañado de lágrimas y semen.

Se subió los pantalones. Picoteando de los platos dijo: «No hacía falta esto, no venía a comer». Desde el suelo, el llanto era ya un lamento. Mientras salía, dando un portazo, añadió: «No cambiarás, no se puede estar con una mujer que siempre está llorando».

Pasó el invierno y plantaba tulipanes en su nueva casa. En ese momento, alguien, lejano, escuchaba una voz mecánica: el número marcado, ya no existe.

Teresa Lampérez Alonso 


\section{CIEN PALABRAS}

Me piden que escriba cien palabras para definir lo que siente una mujer cuando recibe una paliza infernal, que describa el horror, la violencia, la angustia, el odio, la vergüenza, el llanto ahogado... el dolor, la nada, el vacío, el puñetazo, los insultos... los niños llorando. Vuelvo al horror, el silencio, la nada, la soledad, el vacío.

No siento nada, lo siento todo. Suena un largo pitido, me brota sangre de la nariz, intento limpiar el suelo, siento dolor, no siento nada, estoy muerta... Estoy sola, estoy vacía... lloro. Las lágrimas se mezclan con mi sangre... el ojo está negro y el labio inflamado, mi pulso tiembla, no puedo moverme y lloro... lloro... lloro...

Voy sintiendo, voy oyendo, voy recordando, lloro, empiezo a chillar, empiezo a ser... Aún no puedo moverme, me tomo tiempo... estoy muerta, estoy vacía... respiro.

Isabel Lloret Sos 


\section{HERENCIA}

-iiiZorra!!! ¡Te vistes así para provocar! ¿De dónde sacaste eso? ¿Quién te lo dio, eh? - de un manotazo le arrancó la blusa y le levantó la falda. -Te voy a enseñar lo que es bueno, ¡estúpida! La cogió de los pelos, le tapó la boca y justo cuando iba a lanzarla contra la pared, se abrió la puerta de la cocina.

- ¡Silvya! Ven a comer que se enfría.

-Ya voy, mamá.

Vistió rápidamente a su muñeca, le dio un beso y la acostó en su camita.

Luz Marina Álvarez 


\section{NEXXXT}

El Nexxxterotismo hizo disminuir la esclavitud sexual del siglo xxI. Los clientes consideraron obsoletos los burdeles. Ahora preferían el placer sin límites que proporcionaba la tecnología Nexxxt.

La nueva era del entretenimiento sexual: periféricos ultra anatómicos, comunidad en red..., todo lo que el puritanismo pervertido siempre vetó.

Nexxxt Corporation donó gran parte de sus beneficios para que se reconfiguraran meretrices de cualquier nacionalidad.

Elija accesorio. Pulse Enter.

José Ramón Martinez García 


\section{MAR ENLLÀ}

Com més bracejava, més deixava enrere la irrespirable argolla que l'emmanillava a terra. Per fi se sentia lliure i l'aigua li ho recordava com un bateig sense límits que la ingressava en un futur d'ulls oberts i somriures frescs.

De sobte, va endevinar l'altra costa. Una nova terra en què no hauria d'acotar el cap, ni escoltar cap gest caïnita, ni lliurar-se en penitència com un trofeu d'obligada submissió.

En xafar la platja, així que va començar a endreçar els passos cap a una esperança de rialles daurades com l'oli de la felicitat, l'ombra acerada d'un núvol li va embolcallar el cos d'un calfred humit de realitat innavegable. A l'aguait, un rall...

Pasqual Mas 


\section{MALTRATO 3}

Me quiero y me siento querida, después de ocho años creo que puedo comenzar de nuevo, consigo mirarme al espejo sin bajar la mirada, descubro que la bondad existe, puedo mirar a un hombre a los ojos y errar sin esperar que la ira de otro se desplome sobre mí. Quiero gritar sin temor y contarte a ti que sufres el terror dentro de tu propia casa que se puede escapar, que eso no es un hogar, que el miedo no une, que la sumisión no cambia al maltratador. Yo lo conseguí y tú también lo harás.

María del Carmen Merino Pastor 


\section{JOYEUX NOËL}

Benvolgut Pare Noel, aquest Nadal vull que em deixes a l'arbre moltes carmanyoles. Al meu pare no vull que li portes res.

Em dic Vicent i visc al Grau de Castelló de la Plana.

Rosa Miró i Pons 


\section{SÓC. ESTIC. SÓC}

Sóc. Estic. Sóc.

Per mi. Per les meues filles.

Sense tu.

Per mi. Pels meus fills.

Sense tu.

Per mi. Per mi. Per mi.

Sóc. Estic. Sóc.

Rosa Montañés 


\section{LAS PALABRAS TAMBIÉN HIEREN}

No soportamos el dolor de un pinchazo, no nos gusta sentirnos congelados de frío en pleno invierno ni tampoco nos gusta el contacto de una llama en la piel... ¿Por qué aguantamos entonces que nos hieran con palabras?, ¿cómo soportamos el dolor de los insultos?, o ¿por qué consentimos una humillación? Realmente, ¿queremos convencernos de que alguien que nos quiere nos trataría así?

Quizás resulte fácil dejar que nos anulen, quedarnos a un lado y aceptar que los demás decidan por nosotros, o incluso pensar que simplemente estamos destinados a fallar continuamente. Lo difícil es conseguir alejar de nosotros esa llama que tanto daño nos hace, y darnos cuenta de que el problema no es nuestro.

Ma Cristina Morales Carrasco 


\section{EL HASTÍO DE LA CERTEZA}

Por no matar la esperanza, ella quedó con un hombre. Él le repitió varias veces: “¿Qué guapa eres!» Mientras calculaba el perímetro de sus pechos sin afrontar la mirada.

Ella dijo para sí misma: «iAy! si pudieras imaginar mi verdadera belleza..."

Se despidió cortés y se fue triste.

Osadía 


\section{MOLTS HOMES}

Molts homes et miren quan passes pel carrer. Ets bonica, graciosa i amargada.

Molts homes et xiulen quan et veuen passar. Ets jove, guapa i desgraciada.

Molts homes et diuen paraules que sols defineixen el teu físic quan camines a prop d'ells. Ets preciosa, encisadora i menyspreada.

Caterina Palatsí Pinyana 


\section{ME PREGUNTO}

Pero, por qué, por qué a mí... sus palabras bloquean mi mente, sus insultos golpean mi cabeza, su rabia enciende mi dolor y su frialdad apaga mi corazón... pero, por qué, por qué a mí...

Cuántos deseos sin cumplir, cuántas esperanzas sin llegar, cuántas ilusiones sin vivir y cuánto amor sin compartir... pero, por qué, por qué a mí...

Elena Pérez Senabre 


\section{A FER LA MÀ}

Que la culpa que et faça mal el queixal és tota meua perquè no porte un calmant per a tu, a la bossa i, en canvi, no m'oblide mai del pintallavis?

Que has augmentat de pes pels menjars que prepare, i que te'n pose massa al plat?

Que quan arribaré a casa, que ja porte 10 minuts de retard i tens gana de sopar?

Que com és que la camisa que volies posar-te encara està sense planxar? Vaig a dir-t'ho: «que no te n'aniràs...?»

Carme Pinyana i Gari 


\section{ANOCHE SOÑÉ...}

Con cruzar con unas miradas consumidas por la pantalla del ordenador...

Con atrapar una sonrisa dedicada a los que estamos sentados al otro lado...

Con caminar tras unas pequeñas huellas al lado de otras huellas más pequeñas...

Con escuchar una dulce y melodiosa voz desde una habitación infantil antes de que se apague la luz...

Con unas manos con las uñas pintadas de rojo trayendo más sabor a la mesa...

Con oler una fragancia tímida de azahar contra el viento de la noche...

Luego, me he despertado y no he visto a nadie. Y entonces he preguntado, ¿a qué planeta hemos llegado?...

Tahirisoa Rakotonanahary 


\section{OTRA VIDA}

No trabajar en el campo era lo único que yo quería. Mi madre me decía que soñar con otra vida es peligroso. Que la gente se pierde en el camino. ¡Qué sabrá ella, pensaba yo!

Y ahora, aquí, sola, en este cuarto mugroso. Pasando frío, hambre y teniendo que soportar a esos babosos sobre mí... ¿qué tengo? Sólo las ganas de que todo salte por los aires, de que uno de esos cabrones que me trajeron aquí engañada, con la promesa de una vida mejor, termine por cumplir sus amenazas y me vuele la cabeza.

Carmen Ramirez 


\section{INMUTABLE}

Mi cuarto en el palacete modernista de Sant Gervasi era tan sórdido que parecía de otro barrio. Además Adrià Frument, hijo, me asaltaba día sí, día también. Menos mal que yo tenía mis truquitos para no quedarme embarazada.

Allí limpiaba las vidrieras emplomadas, fijaba en alto las ventanas para airear las estancias y daba esplendor a la colección inmensa de metales.

En cuanto ahorré lo suficiente me vine a Wiesbaden, la Niza del Norte. Trabajo en un balneario. Aquí cuento con dos grandes bazas para que mi vida mejore a partir de este año que ahora comienza: las nociones de alemán adquiridas durante mi tercera filología y la certeza de que al administrador no le interesan nada las mujeres. Así que bienvenido o willkommen 2020.

Rosario Raro 


\section{LA HUÍDA}

Se despertó en mitad de la noche, no podía dormir, fue a por sus hijos. Un impulso la llevó a huir y no mirar atrás.

Pero no pudo, él se levantó. Le imploró que no huyera, pero los puños no imploran, los puños matan.

Mamá, mamá ya no está... se la llevó papá.

Estaba tan preocupada por los monstruos que le acechaban en sus pesadillas, que no se dio cuenta que ahora, dormía uno junto a ella.

Eva Sales Fortanet 


\section{MIEDO}

Se levantó, una mañana más, una mañana como las muchas mañanas anteriores. Con miedo. Miedo a reconocer no era solo una mala racha, tensiones en el trabajo, un mal momento que no se repetirá... no, no era nada de eso. Era algo que había que llamar por su nombre. Un nombre que no se atrevía a decir. Eso no podía estar pasándole a ella. Sí, esa mañana se levantó con miedo. Un miedo distinto. Miedo a perder el miedo que la hiciera reaccionar.

Dora Sales Salvador 


\section{LA SECTA}

Empecé a darme cuenta pronto que mi marido tenía razón. Era mejor que él administrara el dinero en casa porque así yo podía encargarme mejor de las niñas. Así que confié en él.

También me hizo comprender que mi familia era repugnante y sólo nos hacía la vida imposible para separarnos. Así que decidí dejar de hablarme con todos ellos.

Además, empecé a comprender que, cuando las cosas iban mal, bebía mucho, pero era porque necesitaba descargar esa presión. Así que esperé a que cambiara.

Del mismo modo, le creí cuando me decía que era una basura y una inútil y que sólo él podría protegerme de todo lo malo en la vida. Así que me quedé a su lado.

Encerradita en una habitación oscura estoy. Me siento protegida porque no me pega; me siento querida porque dice que me ama; me siento acompañada porque me dio a mis hijas... pero creo que algo no va bien.

Lidón Sancho Ribés 


\section{ESTOY INQUIETA}

Estoy inquieta. Algo pasa dentro de mí que no logro saber qué es. Me falta la fuerza vital. Me falta el aliento.

Mi alrededor permanece oscuro, pintado de un bonito negro azabache. Será la noche.

Tiemblo; el frío penetra en mis huesos, como cuchillos helados, hiriendo mi cuerpo. Será el invierno.

Algo se resbala por todo mi cuerpo, cayendo en el suelo; me toco, estoy empapada. Será la lluvia.

Noto un ruido, noto un golpe que retumba en todo mi cuerpo como una hermosa partitura. Será un trueno.

¡Escucha! ¡Escucha!... ¿ No oyes?... Esa voz... ¿Quién grita mi nombre?... Yo conozco esa voz... No puedo moverme... Estoy inquieta.

Maribel Sancho Ribés 


\section{UN DÍA EN EL ALMACÉN}

Hace años que Juan ha mejorado en su situación laboral. En el almacén de naranja ya no carga peso, las nuevas máquinas lo hacen por él. El tiempo que le sobra fuma y coquetea con las jóvenes encajadoras. En cambio a Carmen la encajadora la reforma le ha perjudicado. Antes si se cansaba, se apoyaba en la mesa de la compañera de atrás, pero dicen que eso las relaja y no les cunde el trabajo. Ahora están de cara a la pastera. Fichan para todo, hasta para ir al lavabo, no pueden hablar y si la naranja no está equilibrada y cuesta más de encajar, son insultadas desde lo alto como animales.

Pilar Sanjulián 


\section{LUNA DE HIEL}

Le miró dormir con el ojo que no estaba morado. La cabeza plácida sobre el almohadón de plumas. Se despidió de la hermosa cesta de frutas tropicales. El velo envolvió las marcas violáceas. Se asomó a la ventana. La luna esparcía sobre los tejados de los hoteles charcos de luz fría moteados con destellos carmesíes. Con el ramo envejecido entre las manos echó a volar.

Verónica Segoviano Marinas 


\section{NO ES UN DÍA CUALQUIERA}

Siete de la mañana. Se despierta sobresaltado. El otro lado de la cama, aún caliente, está vacío y la puerta de la casa se ha cerrado suavemente. Ella baja la escalera decidida. En las calles, apenas se cruza con nadie, pero ya sabe que no está sola. Camina, taconeando con firmeza y, por primera vez en muchos años, agradece el sol otoñal que acaricia sus mejillas. Se acabó pensar en qué hacer, el sentirse poco menos que nada, y sonríe levemente... por fin.

Carmen Senabre Llabata 


\section{LA FLOR}

Era una de las flores más bonitas del jardín, con una carrera brillante y unos hijos maravillosos. Él siempre la admiró. Pero por desgracia, un día, en contra de su voluntad, enfermedades de la vida, esa flor poco a poco se fue marchitando. Ya no era bonita, ya no podía cuidar de sus hijos, ya no avanzaba en su carrera. Él ya no la admiró, él la anuló. Nunca supo apreciar que sus ojos no dejaran de brillar.

Marta Senent Ramos 


\section{DINS DE CASA}

Tot va bé, cada vegada estem més lluny de tu. Dins de casa ha eixit el sol. La llum és diferent ara, més clara, més suau, tot és més lluent, pareix més net.

T'has deixat per ací unes quantes coses que sabem que no vindràs a per elles, així que les tirarem: un tros de mantega rància fosa en el pa nostre de cada dia, els contes del sàtir de la llet calenta, el teu títol de mestre i el baluern del teu nom.

María José Senent 


\section{ROTA Y DESGASTADA}

Dormía plácidamente cuando ella se deslizó de nuevo sobre el mullido del sofá. Lo miraba mientras se alejaba midiendo con prudencia sus pasos para ausentarse por un tiempo limitado, pues jugaba con la suerte de que los somníferos disueltos en el whisky hicieran el efecto que indicaba el prospecto.

Un poco más tarde, volvía a entrar por aquella puerta de madera rota y desgastada. En aquel momento sońaba despierta; anhelaba el momento en el que sentada en una de aquellas butacas contemplaría las nubes desde arriba, y sería libre.

Miriam Solsona Andrés 


\section{DESDE LA VENTANA}

Desde la ventana de un bar, una tarde de invierno, la vi. Recorría la calle de arriba abajo y en cada farola, en cada papelera, en cada hueco entre los muros, pegaba cuidadosamente un cartel. Otra desempleada más, pensé con tristeza, ofreciéndose a cuidar niños... o a traducir textos del hebreo. Acabé el café y al salir hacia el frío miré distraídamente los enormes trazos de una times de imprenta. La frase allí escrita me golpeó con furia y me llevó al mundo de una mujer conquistando su propia historia: "QUE LO SEPAS: ME PIENSO VESTIR COMO ME DÉ LA GANA.»

Rosalia Torrent Esclapés 


\section{POR}

Por de dir qualsevol cosa que et provoque. Por dels teus irònics somriures. Por dels teus setze anys. Por de no encertar-ho mai. Por de fer-ho tot malament. Respiració entretallada, inquietud, comprovació ansiosa del sopar amanit: truita de pataca. Tornada a la saleta. Canal esportiu adient. Por. Fi del meu concurs de paraules. Visita al bany, de nou. Tornada a la cuina per rescalfar el sopar. Por. Sis minuts i Tara es posarà a lladrar. Por. Tres minuts i em quedaré quieta, amb la taula parada. La seua gossa i jo, les dos en alerta. Por. A la fi, els seus passos. La seua clau. La seua presencia. La seua gossa. El seu menyspreu. Tot és seu. Menys la por, que és meua.

Adela Torres 


\section{COLOR FAVORITO}

Mi color favorito desde niña es el morado. Siempre pintaba de morado el cielo de mis dibujos. Teñí de morado el balón de mi hermano. La parte de abajo de los cojines del sofá de la abuela todavía tienen mis garabatos morados. Incluso las paredes del comedor de casa las decoré con trazos de este color. La mayor parte de mi armario es una rica gama de morados.

Hoy, mi hija me ha regalado un dibujo. En él estábamos toda la familia. Mi cara estaba pintada de morado.

El morado es el color que más odio. 


\section{LA VIOLÈNCIA DE GÈNERE}

Què és la violència de gènere?

Hom podria pensar que la violència de gènere és sofrir colps, bufetades, empentes per part del cònjuge; doncs sí, aquest comportament és violència de gènere. Malauradament la violència de gènere no acaba en estes accions, i hi pot ser callada, soterrada, disfressada, en ser ignorats els teus drets com ésser humà. Dret a opinar, dret a emmalaltir, dret a gaudir de certa llibertat, dret a diferir...

Ferrana Vila 


\section{SOY FEMINISTA, LOS MACHISTAS LEJOS}

Yo entonces tenía una gran dependencia emocional y mi autoestima estaba por los suelos. No pude llorar durante mucho tiempo. Imagínate lo bloqueada que estaba. Imagínate las primeras vacaciones tras la separación. Le quitó el móvil al niño y le prohibió que me llamara cuando estaba con él. Ahora te lo puedo contar porque no entro en la emoción como antes. Él me decía que no iba a poder mantenerme sola y que ya vería lo que me tenía preparado. El miedo no se me pasaba nunca. Fíjate lo sumisa que llegué a ser. Todo empezó a cambiar cuando fui consciente de ello. Ahora me digo: «Soy feminista. Los machistas lejos». Ahora sé lo importante que es concienciar para que no se repitan las historias.

Amparo Zacarés 


\section{ÍNDEX}

A vida o muerte. María Luisa Agost .................................................................. 8

Inesperado. Miguel Alayrach Martínez............................................................ 9

El velo hierático de la violencia de género.

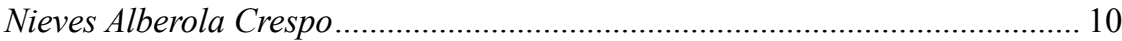

Historia contada. Inma Alcalá García ............................................................. 11

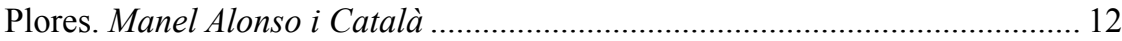

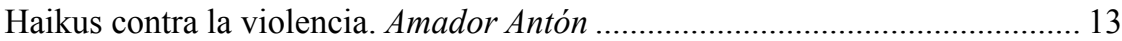

Sense paraules. Eugenia Aragó................................................................... 14

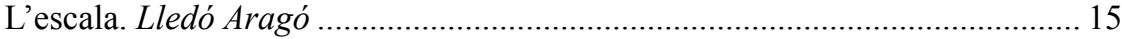

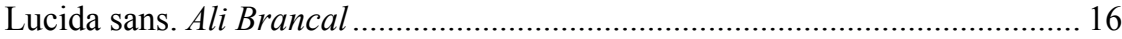

A ella siempre le había gustado el rojo intenso de su barra de labios. Luisa Busto...... 17

Señoras, por favor, limpien. Lidón Caballero Guiral .................................... 18

L'aniversari. Cristina Cabedo Laborda ............................................................. 19

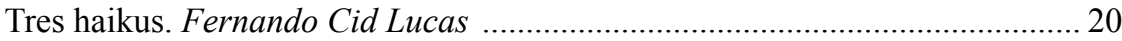

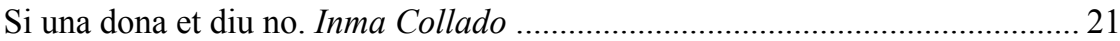

Campo de amapolas. Carmen Corona Marzol ................................................. 22

Va pensar que no hi havia sortida. M. Creu Marín ............................................. 23

El último picnic. Manolo Dos Ramos ......................................................... 24

Ecos en el patio. Sebastián Esparducer Gargallo ........................................... 25

Superfluo vestido. Estudiantado de $4^{\circ}$ de Grado en Publicidad de la UJI .................... 26

Ferma. Maria Estupiñá Mulet ...................................................................... 27

Eres mi vida. Verónica Fernández Guillén .................................................... 28 
Cadáver exquisito en red. Carmen María Fernández Nadal

y Juncal Caballero Guiral ................................................................................ 29

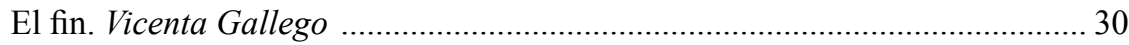

Telaraña. Javier García .................................................................................... 31

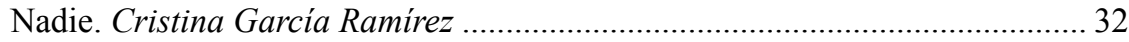

No todos son así. Inés García Ramírez ........................................................... 33

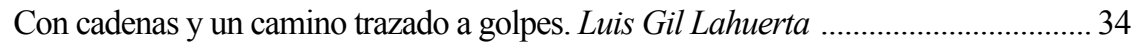

Sobreviviente. Elisa Iniesta Pérez de Gracia ................................................. 35

Un hombre en casa. Ana María Julián Edo ....................................................... 36

Tot enrere. Cristina Laborda Martínez ……...................................................... 37

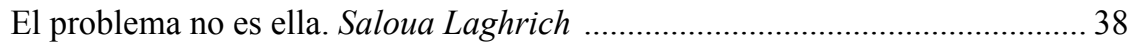

Tulipanes. Teresa Lampérez Alonso .................................................................. 39

Cien palabras. Isabel Lloret Sos ................................................................... 40

Herencia. Luz Marina Álvarez .......................................................................... 41

Nexxxt. José Ramón Martínez García ......................................................... 42

Mar enllà. Pasqual Mas ................................................................................ 43

Maltrato 3. María del Carmen Merino Pastor ................................................... 44

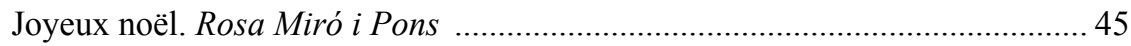

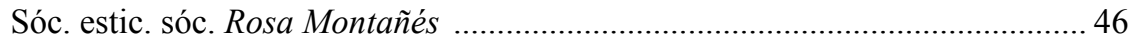

Las palabras también hieren. $M^{a}$ Cristina Morales Carrasco ........................... 47

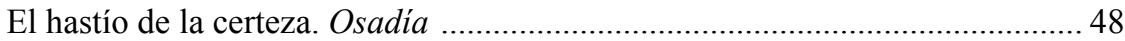

Molts homes. Caterina Palatsi Pinyana ......................................................... 49

Me pregunto. Elena Pérez Senabre ................................................................ 50

A fer la mà. Carme Pinyana i Garí .................................................................. 51

Anoche soñé... Tahirisoa Rakotonanahary ................................................... 52

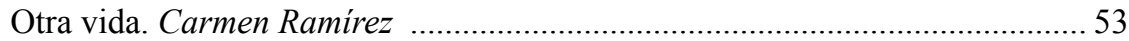

Inmutable. Rosario Raro ............................................................................... 54 


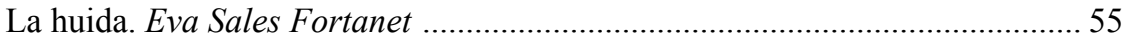

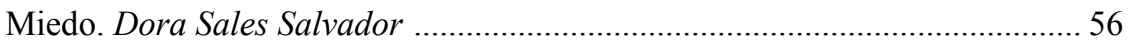

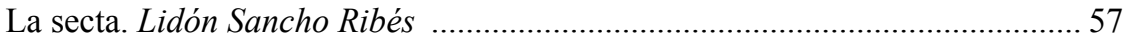

Estoy inquieta. Maribel Sancho Ribés ........................................................ 58

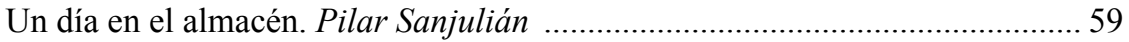

Luna de hiel. Verónica Segoviano Marinas .................................................... 60

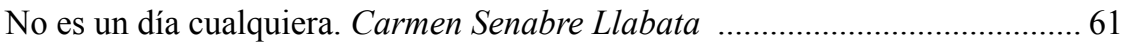

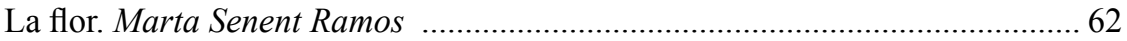

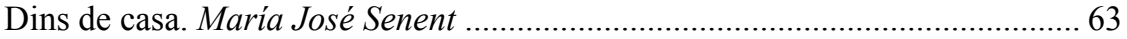

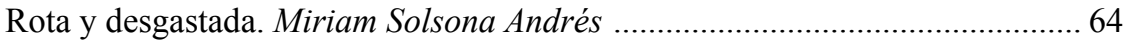

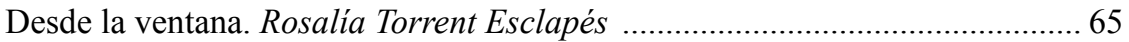

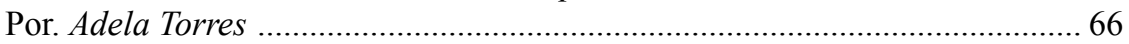

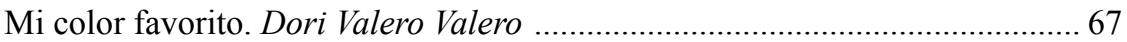

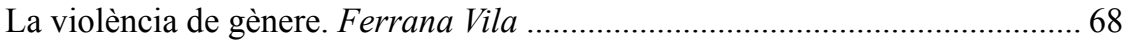

Soy feminista, los machistas lejos. Amparo Zacarés ..................................... 69 
